International Journal of Automotive and Mechanical Engineering ISSN: 2229-8649 (Print); ISSN: 2180-1606 (Online)

Volume 15, Issue 2 pp. 5178-5194 June 2018

(C) Universiti Malaysia Pahang, Malaysia

DOI: https://doi.org/10.15282/ijame.15.2.2018.3.0400

\title{
Tri-Axial Vibration of the Head of Car Driver under Different Seating Conditions
}

\author{
N. Nawayseh \\ Mechanical Engineering Department, College of Engineering, University of Sharjah, \\ Sharjah 27272, United Arab Emirates \\ Email: nnawayseh@sharjah.ac.ae \\ Phone: +97165053947; Fax: +97165585191
}

\begin{abstract}
Previous studies have quantified the biodynamic responses to vibration in a laboratory set-up using mainly rigid seats and single axis excitation. This study investigates the effect of the backrest contact, headrest contact, backrest angle, arm angle and the extent of gripping the steering wheel on the acceleration of the head in a real life multi-axis vibration environment. Fifteen male subjects drove a car on a paved road at a speed of $40 \mathrm{~km} / \mathrm{h}$ adopting one of eight seating conditions at a time. The acceleration of the head was measured in the $\mathrm{x}, \mathrm{y}$ and $\mathrm{z}$-directions during the exposure duration. The results were presented as r.m.s. values and PSDs of the accelerations of the head. The greatest effect on the acceleration of the head resulted from using the backrest and the headrest. The arm angle and the extent of gripping the steering wheel showed no or little effect on the acceleration of the head. The effect of the seating conditions was found generally different from that reported in studies conducted in the labs with single, dual, or tri-axial vibration exposure.
\end{abstract}

Keywords: Multi-axis, whole-body vibration, seating conditions, acceleration of the head, field study.

\section{INTRODUCTION}

The effect of the seating condition on the biodynamic responses to vibration in a reallife multi-axis vibration environment is not well established in the literature. The vast majority of the studies have focused on single axis vibration exposures $[1,2]$ despite the considerable differences reported between the biodynamic responses measured with single axis vibration and those measured with dual or multi-axis vibration [3-6]. Moreover, the majority of the previous studies were conducted in the laboratory with human subjects sitting on a rigid seat [2,3,5,7-10] which has a response different from the soft/compliant seat used in real life. In addition, in the previous experimental and modelling studies more attention was given to the passengers' sitting posture than to the driver sitting posture [11-13].

Measuring the biodynamic responses to vibration using rigid seats helps in understanding how the human body system responds to vibration under certain conditions. However, the seat system and the human body system act as one coupled system in which the response of either system influences the response of the other $[14,15]$. Consequently, the biodynamic responses obtained with rigid seats may not necessarily represent the biodynamic responses obtained with compliant seats. Hence, experiments with compliant vehicle seats will perhaps be more appropriate and representative than with rigid seats. 
Vibration in vehicles occurs in 6 axes simultaneously (3 translational and 3 rotational) with the magnitude of vibration differing among the different axes. The rotational motion could be induced by the roughness and characteristics of the road and/or by the non-rigid base on which the seat is mounted [16]. Fore-and-aft motion may also induce pitch motion especially at the backrest of the seat. In fact, the response measured along any translational axis is composed of the response to the vibration along that axis, the cross-axis response to the vibration along the other translational axes, and the response due to the rotational motion about the axes perpendicular to the axis along which the response is measured. For example, the fore-and-aft acceleration measured on the head in a real life six axes vibration environment (a vehicle) consists of three components. The first component is the fore-and-aft acceleration resulting from the vibration in the fore-and-aft direction. The second component is the fore-and-aft crossaxis acceleration resulting from the vibration in the vertical and lateral directions. The third component is the fore-and-aft acceleration resulting from the rotational motion about the lateral axis (pitch motion) and the rotational motion about the vertical axis (roll motion). The motions in those 6 axes may or may not be correlated with each other. So, measurements in the laboratory even with tri-axial excitation may not necessarily represent the responses measured in the field.

Several studies have investigated the effect of the seating condition and the sitting posture on the biodynamic responses (e.g. the apparent mass and transmissibility). The effects of using a backrest, backrest angle and seat surface angle were among the studied factors. However, only a few studies considered the driver position $[17,18]$.

Studying the human body exposure to vibration in 6 axes can be performed in the laboratory using 6 degree-of-freedom shakers. One can measure the vibration in a vehicle in the 6 directions and reproduce it in the lab using a 6 degree-of-freedom shaker to obtain a more representative real-life exposure. However, most laboratories do not have such an expensive facility. Moreover, the procedure of measuring the vibration in the 6 axes and reproducing it in the lab is costly, complicated and time consuming. The obvious alternative is to conduct the study in the field using a real vehicle such as in $[14,19,20]$.

The objective of this work is to investigate the vibration of the driver's head in a multi-axial real-life vibration environment. The effect of the contact with the backrest, backrest angle, contact with the headrest, arm angle, and the extent of gripping the steering wheel on the vibration of the head in the $\mathrm{x}, \mathrm{y}$, and $\mathrm{z}$ directions will be studied. Some of those conditions were reported to have affected the biodynamic responses under single axis vibration but little effort has been made to study their effect under multi-axis vibration especially in real life environment [4]. It was hypothesised that changing the seating condition will change the driver's posture as well as the transmission path of the vibration to the head resulting in different head vibration with different seating conditions. The effect of the seating conditions measured in this work will be compared with those measured in the laboratories.

\section{EXPERIMENTAL DESIGN AND DATA ANALYSIS}

\section{Apparatus}

A 2009-model SUV car with an engine size of 4.0 litres was used in this work. The odometer reading of the car at the time of the experiment was around $110,000 \mathrm{~km}$ and 
the tyres were one-year old. The tyres pressure was kept at $250 \mathrm{kPa}$ throughout the experiment. The accelerations under the driver seat, on the steering wheel and at the forehead of the subjects were measured using ADXL355 MEMS tri-axial accelerometer. Due to its light weight and proper size, the accelerometer was attached to the forehead of the subject using double-sided tape. The signals were acquired at a sampling rate of $512 \mathrm{~Hz}$ using DT9839E data acquisition module and QuickDAQ software. The data were saved to a laptop for off line analysis. Figure 1a shows the instruments used in the experiment.

\section{Input Vibration}

The car was driven over a paved parking area as shown in Figure 1 (b) at a speed of 40 $\mathrm{km} / \mathrm{h}$. The total duration of vibration exposure was around 60 seconds for each condition. The paved parking area was always uncrowded which guaranteed conducting the experiments without interruption. Moreover, the vibration induced by a paved surface is more than that induced by a normal road surface. This is needed for the experiment as the duration of the exposure to vibration was around 60 seconds only. The input vibration at the base of the driver seat and at the steering wheel was measured in the $\mathrm{x}, \mathrm{y}$, and $\mathrm{z}$-directions. To check for consistency of the input vibration for all subjects, the input vibration from the two sources (i.e. seat and steering wheel) was recorded and compared over 3 runs. The power spectral densities (PSDs) of the measured acceleration during the 3 runs are shown in Figure 2 for both input locations. Bearing in mind that the three runs are done in the field (i.e. not in a laboratory), the figure shows an agreement between the results of the different runs except for some cases. Nevertheless, it was decided to run the experiment 3 times for each condition and report the average of the 3 runs.

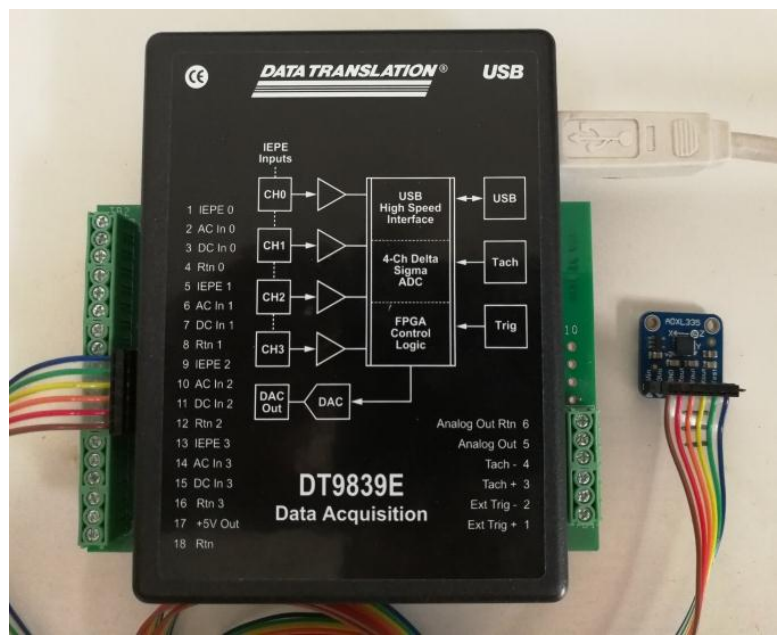

(a)

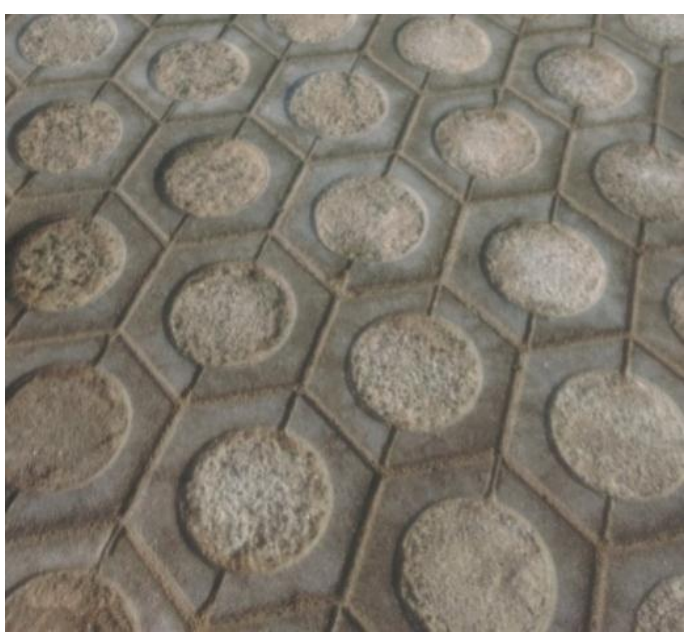

(b)

Figure 1. Photographs showing the (a) instruments and; (b) the profile of the paved road. 


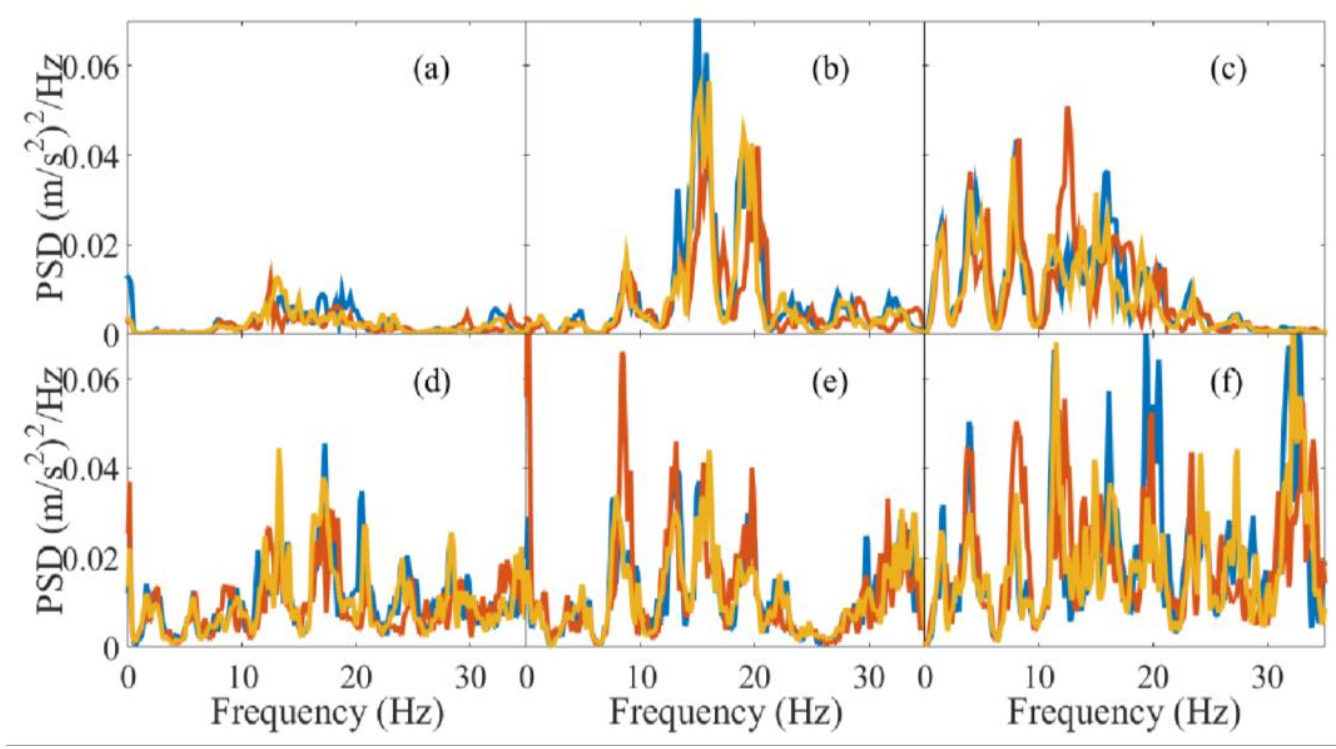

Figure 2. The PSDs of the acceleration measured under the seat and on the steering wheel during three runs. (a), (b), (c): under the seat; (d), (e), (f): on the steering wheel. (a), (d): x-axis; (b), (e): y-axis; (c), (f): z-axis.

\section{Subjects}

Fifteen male subjects, with average mass $75.5 \mathrm{~kg}$ (range 56-92 kg), stature $1.77 \mathrm{~m}$ (range 1.68-1.87 m), age 22 years (range 20-24 years), and body mass index (BMI) $24.1 \mathrm{~kg} / \mathrm{m}^{2}$ (range $18.3-27.8 \mathrm{~kg} / \mathrm{m}^{2}$ ) took part in the experiment. All subjects signed a consent form to participate in the experiment which was approved by the Research Ethics Committee (REC) at the University of Sharjah.

\section{Seating Conditions}

The effects of the backrest contact, headrest contact, backrest angle, arm position (extended or with angle) as well as the effect of the degree of gripping the steering wheel (tightly or lightly) on the vibration of the driver's head were investigated. In the first seating condition, the subjects drove the car while sitting with no backrest contact and no headrest contact, having their arms at an angle and gripping the steering wheel lightly. This condition was assigned the code NB_NH_AA_LG (Table 1) where NB refers to No Back contact, NH refers to No Headrest contact, AA refers to Arm at Angle and LG refers to Light Gripping of the steering wheel. Similar coding was used for the other conditions (third and fourth columns of Table 1). In the second condition, the subjects sat while leaning against a vertical backrest with no headrest contact, having their arms at an angle and gripping the steering wheel lightly (90B_NH_AA_LG). The third and fourth conditions were the same as the second condition but with the backrest inclined at $110^{\circ}$ and $120^{\circ}$ (110B_NH_AA_LG and 120B_NH_AA_LG), respectively. The fifth condition was the same as the third condition but with the subject head in contact with the headrest (110B_WH_AA_LG). The sixth condition was the same as the third condition but with the arms extended (110B_NH_AE_LG). The seventh condition was the same as the third condition but with gripping the steering wheel tightly (110B_NH_AA_TG). The eighth condition was the same as the sixth condition but with the subjects gripping the steering wheel tightly (110B_NH_AE_TG). 


\section{Procedure}

Before starting the experiment, the objective of the experiment and the seating conditions were explained to the subjects. The subjects were then asked to sign a consent form but were told that they could stop the experiment at any time without giving reasons should they decide to do so. The subjects then had some practice to familiarize themselves with the car and to reach the required speed of $40 \mathrm{~km} / \mathrm{h}$ from zero within 5 to 6 seconds. The tri-axial accelerometer was then fixed on the forehead of the subject and the subject drove the car adopting one of the eight seating posture at a time. Recording of the acceleration started when the speed reached $40 \mathrm{~km} / \mathrm{h}$. With each seating condition, the subjects drove the car three times. The order of the seating conditions was randomized among the subjects.

Table 1. Seating conditions schematics, descriptions, and codes.

Seating Description
No backrest (NB)
$\begin{aligned} & \text { No headrest (NH) } \\ & \text { Arm at an angle }(\mathrm{AA}) \\ & \text { Light } \text { Grip of steering wheel (LG) }\end{aligned}$




\section{Analysis}

The root mean square (r.m.s.) of the $\mathrm{x}, \mathrm{y}$ and $\mathrm{z}$-accelerations of the head were calculated in MATLAB for all experimental runs. The average r.m.s. of the three runs of each seating condition were then calculated for each subject. So, the data reported in this work are based on the average of the three runs. The total r.m.s. of the acceleration of the head of each subject was calculated for each condition using Eq. (1).

$$
r . m . s_{\text {total }}=\left(r . m . s_{x}^{2}+r . m . s_{y_{y}}^{2}+r . m \cdot s_{z}^{2}\right)^{1 / 2}
$$

Wilcoxon Signed-Rank Test was used to look for statistically significant differences in the r.m.s. values of the acceleration of the head between the seating conditions. The significance level was taken as 0.05 .

The power spectral densities (PSDs) of the acceleration of the head in the $\mathrm{x}, \mathrm{y}$, and z- directions were estimated in MATLAB using Welch's method [21]. The default Hamming window and 50\% overlap were used in the estimation of the PSDs. When comparing between the different conditions, the PSD shows the change (if any) in the energy at each frequency as a result of changing the seating condition. Hence, the PSD helps in identifying the frequencies at which any change in the head acceleration took place.

\section{RESULTS AND DISCUSSION}

Previous studies on the effect of the seating condition on the biodynamic responses to vibration were conducted under single axis excitation [2,7,13,22-24]. With single axis excitation, the response measured at the head in any direction is due to the single axis vibration. However, in the current multi-axis excitation study, vibration in more than one direction of the 6 directions ( 3 translational and 3 rotational) could have contributed to the measured motion of the head in the $\mathrm{x}, \mathrm{y}$, and $\mathrm{z}$-directions. In addition, previous studies were conducted with enough energy at all frequencies of interest. This allowed the researchers to present their data as transfer functions. In field measurement (such as in this work) some frequencies have more energy than others and some frequencies are with very little energy making presenting the data as transfer functions misleading: even with the low energy frequency, the transfer function is found but it is meaningless [15]. For this reason, the author decided to present the data in terms of the r.m.s. values and the power spectral density of the acceleration of the head.

\section{PSD of the Acceleration of the Head - Without Backrest Condition}

The characteristics of the PSDs of the head acceleration in the three directions (foreand-aft, lateral and vertical) will be described in this section for the position in which no backrest was used (NB_NH_AA_LG). In the subsequent results and discussion subsections, the differences (if any) between the r.m.s. values at different conditions will be explained with help from the PSDs of the accelerations of the head.

With no backrest contact (NB_NH_AA_LG), the power spectral density (PSD) of the acceleration of the head in the fore-and-aft-direction showed 3 peaks as in Figure 3. The frequencies of the peaks were below $0.5 \mathrm{~Hz}$, around $1.5 \mathrm{~Hz}$, and around $4 \mathrm{~Hz}$ (main peak). The magnitudes of the first and third peaks were higher than the magnitude of the second peak. Fore-and-aft transmissibility of the head during fore-and-aft 
vibration showed no distinct peak although the transmissibility was high at frequencies below $4 \mathrm{~Hz}$ and decreased above $4 \mathrm{~Hz}$ [23]. The fore-and-aft transmissibility to the head during separate vertical and lateral vibrations showed peaks at around $4 \mathrm{~Hz}$ similar to that found in this study [23,24]. Peaks at similar frequencies were also evident in the pitch motion and yaw motion of the head during vertical and lateral vibration, respectively $[23,24]$. This may indicate that the main peak at $4 \mathrm{~Hz}$ is caused by rotational motion of the head.

With no backrest contact, the power spectral density (PSD) of the acceleration of the head in the y-direction showed 2 peaks as in Figure 3. The first peak was dominant with a frequency of around $1.2 \mathrm{~Hz}$. The second peak had low magnitude with a frequency of around $3.75 \mathrm{~Hz}$. The first peak (dominant peak at $1.2 \mathrm{~Hz}$ ) is consistent with a previously reported peak in the lateral and roll transmissibility to the head during horizontal vibration [23].

With no backrest contact, the power spectral density (PSD) of the acceleration of the head in the z-direction showed multiple peaks at around $0.25,1.75,2.75$ and 3.75 $\mathrm{Hz}$ in addition to a low broad peak in the vicinity of $8.5 \mathrm{~Hz}$ as in Figure 3. Under vertical vibration only, results from previous studies showed peaks in the vertical transmissibility to the head at frequencies similar to those of the second, fourth and fifth peaks reported in this work [24-26]. A peak with a frequency similar to that of the fourth peak was found in the vertical transmissibility due to fore-and-aft vibration while a peak with a frequency similar to that of the second peak was found in the vertical transmissibility due to lateral vibration [23]. The common peaks appearing in the response measured along a specific direction as a result of a separate single axis excitation in two directions may indicate that the peak is due to rotational motion (mode) that has a component along that specific direction. For example, the peaks appearing in the vertical transmissibility as a result of separate single axis excitations in the vertical and fore-and-aft direction may indicate that those peaks resulted from pitch motion of the head.

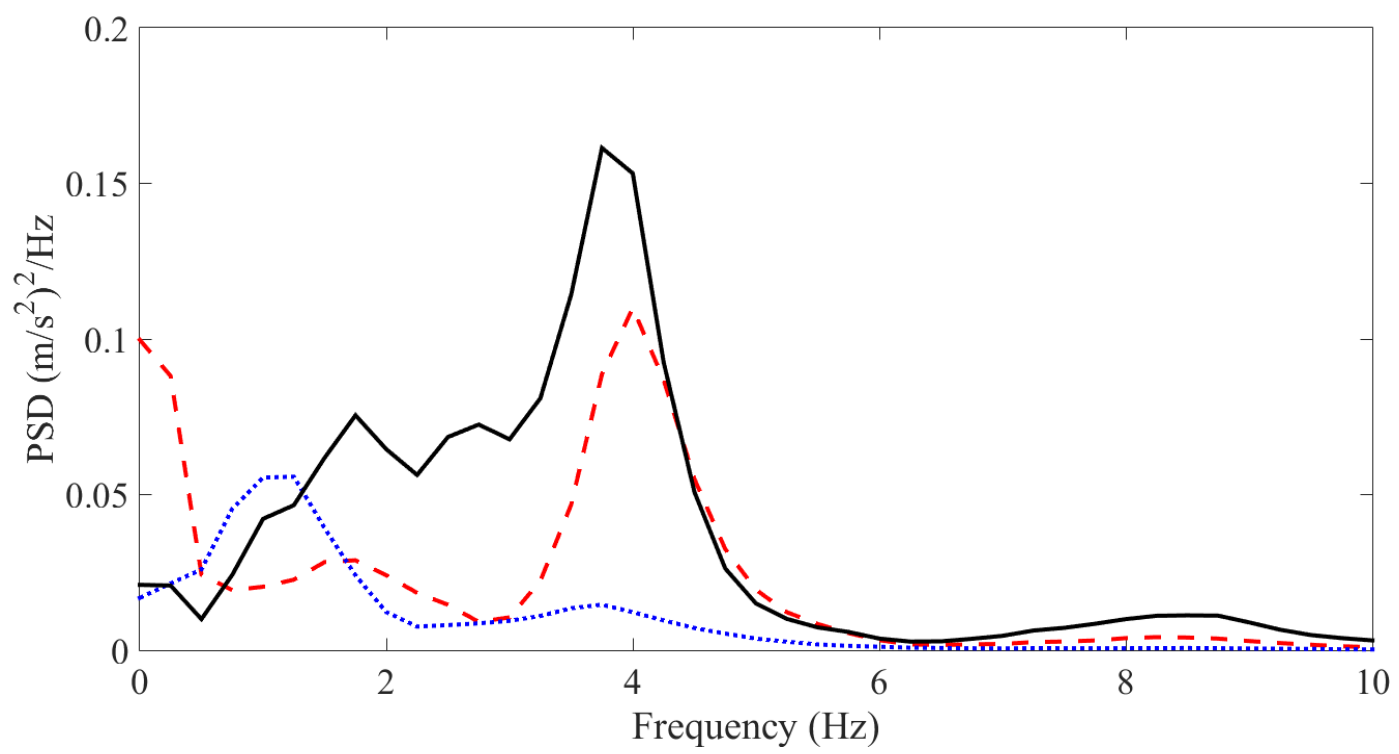

Figure 3. The PSDs of the acceleration of the head measured with the no backrest condition (NB_NH_AA_LG). Dashed line, $\mathrm{x}$-axis; dotted line, y-axis; solid line, z-axis. 


\section{Effect of Using a Backrest}

The r.m.s. values of the acceleration of the head measured with and without using a backrest are shown in Figure 4. No statistically significant differences were found in the r.m.s. value of the acceleration of the head in the x-direction between the no backrest condition (NB_NH_AA_LG) and any of the conditions where a backrest was used (90B_NH_AA_LG, 110B_NH_AA_LG, 120B_NH_AA_LG) (Wilcoxon, p>0.233, Table 2). However, the r.m.s. values of the acceleration of the head in the $\mathrm{y}$ and $\mathrm{z}$ directions were found higher in all the backrest contact conditions than in the nobackrest contact condition (Wilcoxon, $\mathrm{p}<0.05$, Table 2). Similarly, the total r.m.s. value of the acceleration of the head measured with a backrest at any angle was higher than that measured with no backrest (Wilcoxon, $p=0.001$, Figure 4). In all of the compared conditions, the acceleration of the head was greatest in the z-direction and smallest in the y-direction.

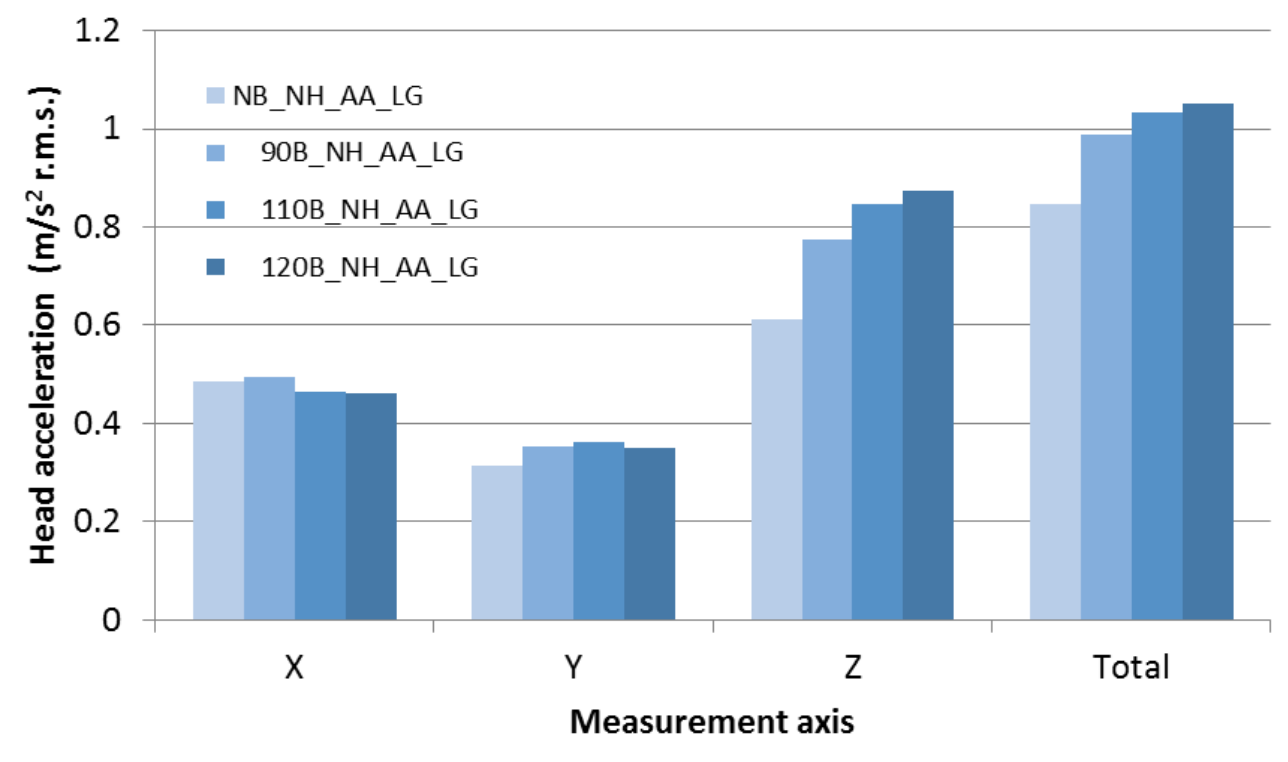

Figure 4. Effect of the backrest and the backrest angle on the r.m.s. value of the acceleration of the head.

The effect of the backrest contact on the PSD of the fore-and aft acceleration of the head depended on the frequency. For example, the contact with the backrest increased the magnitude of the first peak (below $0.5 \mathrm{~Hz}$ ) and decreased the magnitude of the third peak (around $4 \mathrm{~Hz}$ ) as shown in Figure 5. In the region of the second peak (between the first and third peaks) the backrest increased the acceleration of the head at some frequencies and decreased it at other frequencies (Figure 5). With both single axis and dual axis vibration, Mandapuram et al. [4] reported a decrease in the fore-and-aft transmissibility to the head at frequencies below $6.5 \mathrm{~Hz}$ and an increase in the fore-andaft transmissibility to the head at frequencies above $6.5 \mathrm{~Hz}$ when a vertical backrest was used. Those results seem to agree with the results obtained for the PSD of the fore-andaft acceleration of the head in the current study but only at some frequencies including the frequency of the main peak (at around $4 \mathrm{~Hz}$ ). In other previous studies, using a backrest increased the fore-and-aft transmissibility to the head under single axis foreand-aft or vertical excitation while decreased the fore-and-aft transmissibility to the head in the frequency range 2 to $6 \mathrm{~Hz}$ during lateral excitation [23,24]. Since the fore- 
and-aft acceleration of the head increased at some frequencies and decreased at others with the use of a backrest and since the mentioned changes were generally small, the effect of using a backrest on the r.m.s. values of the acceleration of the head in the foreand-aft direction was statistically insignificant as given in Table 2.

The r.m.s. of the lateral acceleration of the head increased when a backrest was used. The PSD of the lateral acceleration of the head indicates that the significant increase in the r.m.s. values are due to increased lateral acceleration of the head in the frequency range of 0 to $2.5 \mathrm{~Hz}$ (in Figure 5). The PSD also shows that the contact with the backrest, although increased the magnitude of the peak, had no effect on its frequency. The effect of using a backrest on the lateral acceleration of the head is similar to the effect of using the backrest on the lateral transmissibility of the head during single axis excitation in the fore-and-aft, lateral, or vertical directions [23,24].

The r.m.s. of the z-acceleration of the head increased when a backrest was used as shown in Figure 4. The PSDs indicates that the significant increase in the r.m.s. values are due to increased motion of the head in the frequency range of 0 to $6 \mathrm{~Hz}$ which included all peaks except the $8.5 \mathrm{~Hz}$ broad peak as in Figure 5. This is in disagreement with the results reported previously during single axis, dual axis and multi axis vibration where the backrest decreased the vertical transmissibility to the head at low frequencies and increased it at high frequency (above 3 to $5 \mathrm{~Hz}$ ) [3,4,24,25]. In addition, in the current study using a backrest changed the magnitude but not the frequencies of the peaks while in the previous studies, an increase in the frequencies of the peaks was reported when a backrest was used.

The differences between the results obtained in this study and those reported in previous studies could be attributed to several possible reasons. In the present study, the multi-axis environment consists of vibration with translational and rotational components (although the rotational components were not measured). The response of the head in any direction could be due to the direct excitation in that direction in addition to correlated and uncorrelated cross-axis motions from the other directions. This argument could be supported by the results of [27] who reported an increase in the mean effective seat-to-head transmissibility when a backrest was used over the whole studied frequency range (up to $12 \mathrm{~Hz}$ ) which is consistent with the results obtained in the current study. The effective seat-to-head transmissibility takes into consideration the coupling effects between axes in a multi-axial environment [8]. The difference between the results of this study and previous studies could also be due to the different type of seats used in the different studies. In the current study, a real car seat was used in contrast to the rigid seats used in the previous studies: the human body and the seat are a coupled system and hence each subsystem affects the response of the other subsystem [14]. In addition, due to the nature and geometry of the compliant seat and the way the seat pan and backrest are assembled, the phase angle between the accelerations of the head due to direct, correlated cross-axis, or uncorrelated cross-axis excitations will play a role in defining the resultant acceleration of the head. The measurement location could also have contributed to the differences between the results of the current study and those of previous studies: while the acceleration was measured using a bite-bar gripped between the teeth in the studies by $[23,24]$ (for example), it was measured on the forehead in the current study. 
Table 2. P-values for differences in the r.m.s. values of the acceleration of the head between different seating conditions (T: Total).

\begin{tabular}{|c|c|c|c|c|c|c|c|c|}
\hline & Axis & $\begin{array}{c}\text { 90B_NH_ } \\
\text { AA_LG }\end{array}$ & $\begin{array}{c}\text { 110B_NH } \\
\text { _AA_LG }\end{array}$ & $\begin{array}{l}\text { 120B_NH } \\
\text { _AA_LG }\end{array}$ & $\begin{array}{c}\text { 110B_W } \\
\text { H_AA_L } \\
\text { G }\end{array}$ & $\begin{array}{c}\text { 110B_NH } \\
\text { _AE_LG }\end{array}$ & $\begin{array}{l}\text { 110B_NH } \\
\text { _AA_TG }\end{array}$ & $\begin{array}{l}\text { 110B_NH } \\
\text { _AE_TG }\end{array}$ \\
\hline \multirow{4}{*}{$\begin{array}{c}\mathrm{NB}_{-} \\
\mathrm{NH} \\
\mathrm{AA}_{-} \\
\mathrm{LG}^{-}\end{array}$} & $\mathrm{X}$ & 0.955 & 0.233 & 0.233 & - & - & - & - \\
\hline & Y & 0.006 & 0.001 & 0.011 & - & - & - & - \\
\hline & $\mathrm{Z}$ & 0.001 & 0.001 & 0.001 & - & - & - & - \\
\hline & $\mathrm{T}$ & 0.001 & 0.001 & 0.001 & & & & \\
\hline \multirow{4}{*}{$\begin{array}{c}90 \mathrm{~B}_{-} \\
\mathrm{NH} \\
\mathrm{AA}_{-} \\
\mathrm{LG}^{-}\end{array}$} & X & - & 0.14 & 0.125 & - & - & - & - \\
\hline & Y & - & 0.57 & 0.733 & - & - & - & - \\
\hline & Z & - & 0.001 & 0.003 & - & - & - & - \\
\hline & $\mathrm{T}$ & - & 0.012 & 0.031 & - & - & - & - \\
\hline \multirow{4}{*}{$\begin{array}{c}110 \mathrm{~B} \\
{ }_{-\mathrm{NH}} \\
\mathrm{CAA}_{\mathrm{A}} \\
\mathrm{LG}\end{array}$} & X & - & - & 0.82 & 0.001 & 0.82 & 0.041 & - \\
\hline & Y & - & - & 0.233 & 0.001 & 0.125 & 0.233 & - \\
\hline & $\mathrm{Z}$ & - & - & 0.191 & 0.023 & 0.036 & 0.173 & - \\
\hline & $\mathrm{T}$ & - & - & 0.256 & 0.008 & 0.281 & 0.041 & - \\
\hline \multirow{4}{*}{$\begin{array}{l}110 \mathrm{~B} \\
-\mathrm{NH} \\
\mathrm{CAE}_{-} \\
\mathrm{LG}\end{array}$} & X & - & - & - & - & - & - & 0.002 \\
\hline & $\mathrm{Y}$ & - & - & - & - & - & - & 0.427 \\
\hline & Z & - & - & - & - & - & - & 0.82 \\
\hline & $\mathrm{T}$ & & & & & & & 0.124 \\
\hline $110 \mathrm{~B}$ & X & - & - & - & - & - & - & 0.233 \\
\hline _NH & Y & - & - & - & - & - & - & 0.496 \\
\hline _AA_ & $\mathrm{Z}$ & - & - & - & - & - & - & 0.691 \\
\hline TG & $\mathrm{T}$ & & & & & & & 0.427 \\
\hline
\end{tabular}

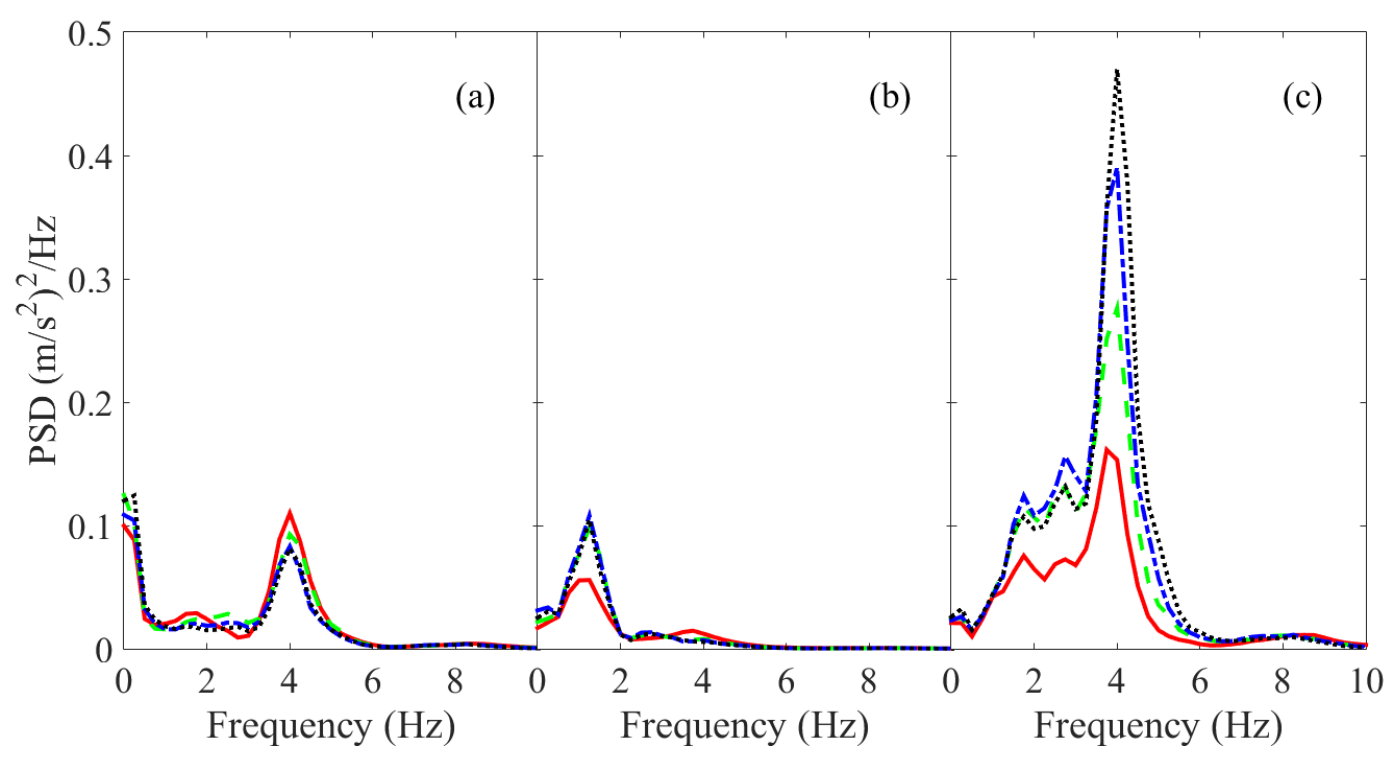

Figure 5. Effect of the backrest and the backrest angle on the PSD of the acceleration of the head. (a), x-axis; (b), y-axis; (c), z-axis. Solid line, no backrest (NB_NH_AA_LG); dashed line, $90^{\circ}$ backrest angle (90B_NH_AA_LG); dash-dot line, $110^{\circ}$ backrest angle (110B_NH_AA_LG); dotted line, $120^{\circ}$ backrest angle (120B_NH_AA_LG). 


\section{Effect of Backrest Angle}

The effect of the backrest angle on the acceleration of the head was investigated by comparing the r.m.s. of the acceleration of the head measured with the backrest inclined at $90^{\circ}, 110^{\circ}$ and $120^{\circ}$ (90B_NH_AA_LG, 110B_NH_AA_LG, 120B_NH_AA_LG) (Figure 4, Table 2). Increasing the backrest angle from $90^{\circ}$ to $110^{\circ}$ or to $120^{\circ}$, increased the acceleration in thse $\mathrm{z}$-direction as well as the total acceleration while had no effect on the acceleration measured in the $\mathrm{x}$ and $\mathrm{y}$ directions (Table 2). However, between backrest angles $110^{\circ}$ and $120^{\circ}$, there was no statistically significant difference in the acceleration in any direction (Table 2).

The PSDs of the acceleration of the head in the $\mathrm{x}$ - and y-directions do not show considerable changes with changing the backrest angle (Figure 5). In most of the frequency range (especially in the y-direction) the PSDs of the different backrest angle conditions are almost identical. Hence, the r.m.s. values of the acceleration in the $\mathrm{x}$ direction and the y-direction were not affected by changing the backrest angle. The absence of an effect for the backrest angle is in disagreement with the effect of backrest angle reported previously using vertical vibration where increasing the backrest angle was found to decrease the fore-and-aft transmissibility to the head in the region of the main peak (around $4 \mathrm{~Hz}$ ) and to increase both the fore-and-aft and vertical transmissibility at high frequencies [26]. In the z-direction, however, the main peak in the PSD of the acceleration (at $4 \mathrm{~Hz}$ ) increased when the backrest was changed from $90^{\circ}$ to $110^{\circ}$ or to $120^{\circ}$ consistent with the increase in the z-acceleration r.m.s. values. The results are also in disagreement with those reported by [26] who showed no significant change in the peak of the vertical transmissibility to the head during vertical vibration. During fore-and-aft vibration of subjects seated on a compliant seat, [28] reported an increase in the peaks of the transmissibility to the head with an inclined backrest compared with a vertical backrest which is consistent with the results obtained in the current study.

\section{Effect of Headrest Contact}

The effect of using a headrest on the acceleration of the head was examined by comparing the acceleration measured at the head with and without using a headrest (i.e. seating conditions 110B_NH_AA_LG and 110B_WH_AA_LG). Using a headrest increased the acceleration of the head in the $x$ - and $y$ - directions (Wilcoxon, $p<0.05$ ) but decreased the acceleration of the head in the z-direction (Wilcoxon, $\mathrm{p}<0.05$ ) (Figure 6, Table 2). The total acceleration of the head also increased with the use of a headrest (Wilcoxon, $\mathrm{p}<0.05$ ).

The PSDs show that using a headrest decreases the PSDs of the $\mathrm{x}$ - and $\mathrm{y}$ accelerations of the head at frequencies below about $1.25 \mathrm{~Hz}$ and significantly increases the PSDs at higher frequencies especially in the x-direction (Figure 7). The magnitude of the second peak of the x-axis PSD (at around $2.25 \mathrm{~Hz}$ ) was accentuated with the use of a headrest as shown in the figure. This explains the increase in the r.m.s. values of the acceleration in the $\mathrm{x}$ - and $\mathrm{y}$-directions when using a headrest. In the $\mathrm{z}$-direction, the contact with the headrest decreased the PSDs of the $\mathrm{z}$ acceleration of the head at frequencies below about $4 \mathrm{~Hz}$ and only slightly increased the PSDs at higher frequencies (Figure 7). Moreover, the peak at $2.75 \mathrm{~Hz}$ disappeared when using a headrest. The effect of using a headrest resembles the effect of using a backrest reported in previous studies during single axis excitation [23,24] as both act as a support for the 
body/head at low frequencies but increase the vibration at high frequencies (although the definition of low and high frequencies depends on the axis of interest as described above). Unfortunately, no previous study has investigated the effect of using a headrest to compare with the results obtained here.

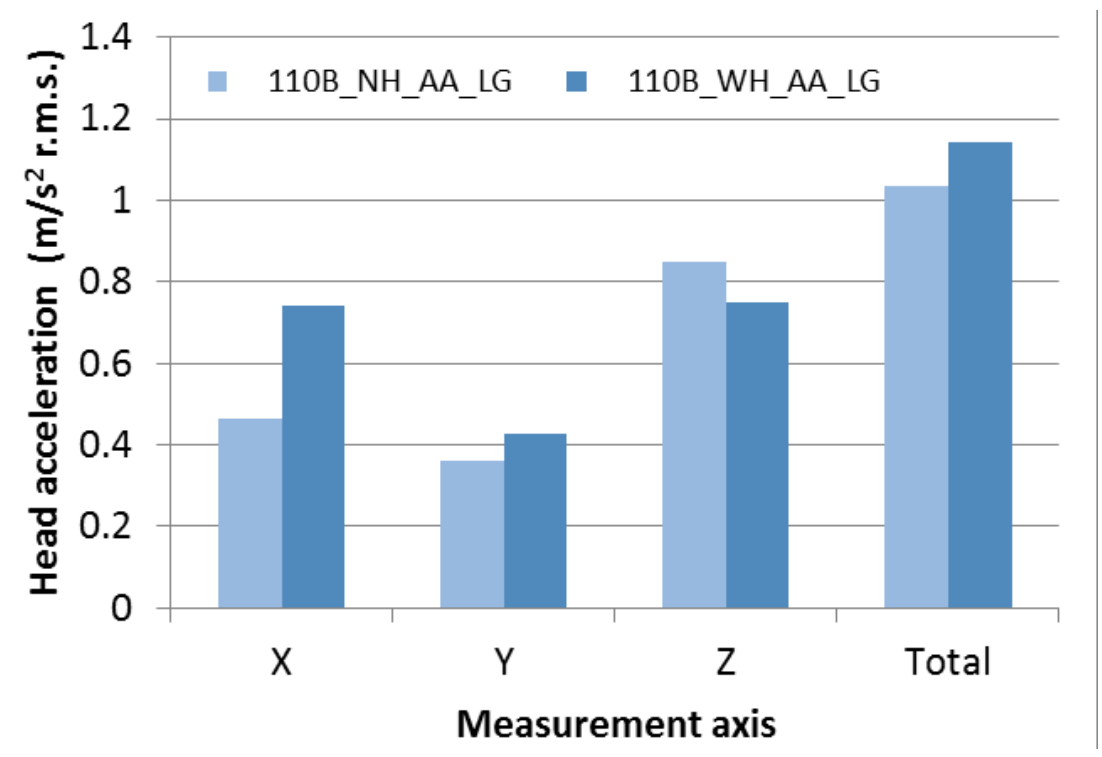

Figure 6. Effect of using a headrest on the r.m.s. value of the acceleration of the head.

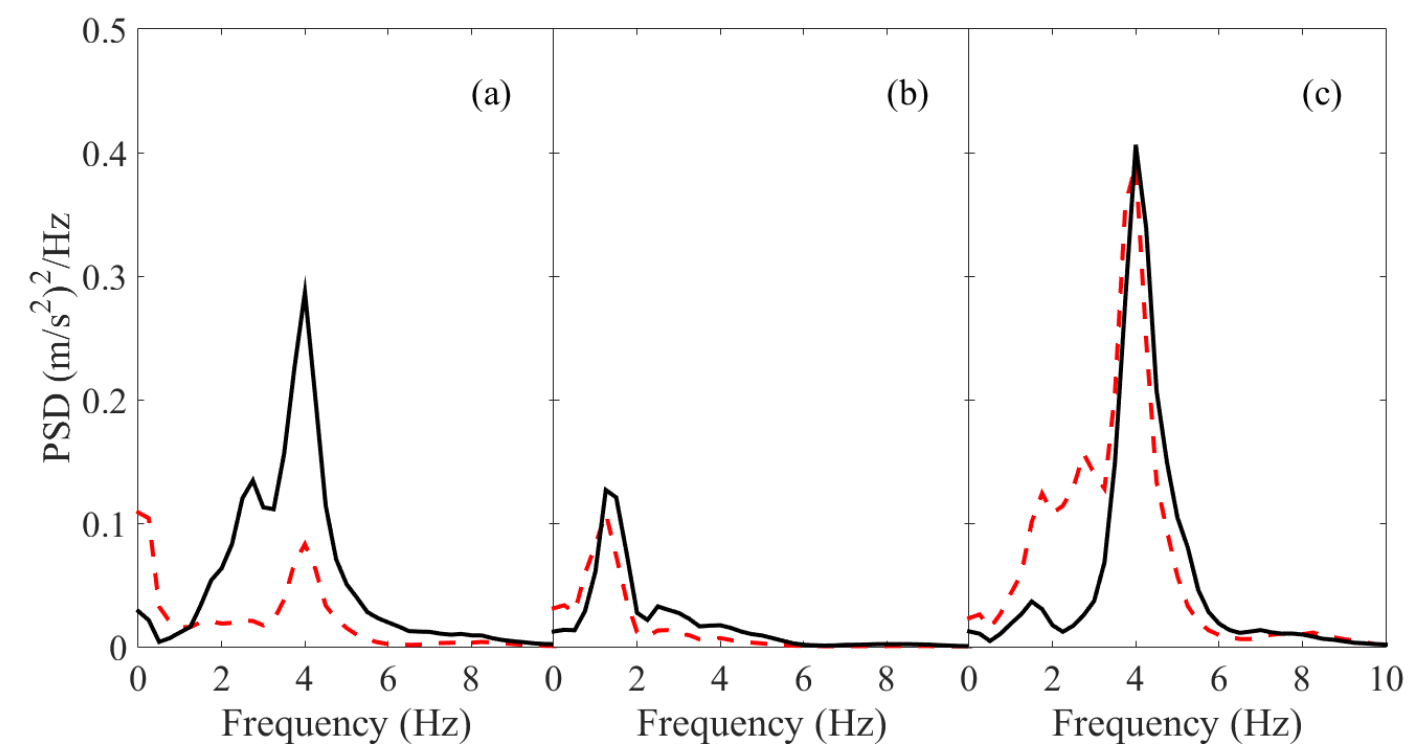

Figure 7. Effect of using a headrest on the PSD of the acceleration of the head. (a), xaxis; (b), y-axis; (c), z-axis. Solid line, with headrest (110B_WH_AA_LG); dashed line, no headrest (110B_NH_AA_LG).

When using a headrest (i.e. seating condition 110B_WH_AA_LG), no statistically significant difference was found between the acceleration measured in the $\mathrm{x}$-direction and the $\mathrm{z}$-direction (Wilcoxon, $\mathrm{p}=1.000$ ). This indicates the importance of including both axes in comfort human body models: while vertical acceleration may 
imply axial deformation of the head-neck system, fore-and-aft acceleration implies shear deformation of the same system.

\section{Effect of Arm Position}

The effect of the arm position on the motion of the head was investigated using two arm positions namely, arm at an angle and arm extended as shown in Figure 8. The effect of arm position was studied once with light gripping of the steering wheel (i.e. the seating conditions 110B_NH_AA_LG and 110B_NH_AE_LG) and once with tight gripping of the steering wheel (i.e. the seating conditions 110B_NH_AA_TG and 110B_NH_AE_TG). With both steering wheel gripping conditions, statistical analysis showed no effect of arm position on the motion of the head in any direction (Wilcoxon, $\mathrm{p}>0.125$, Table 2) except on the vertical ( $\mathrm{z}$ ) motion of the head with the light gripping condition where the vertical motion of the head was higher with the arm extended condition than with the arm at angle condition (Wilcoxon, $\mathrm{p}=0.036$ ).

The PSDs of the acceleration of the head in the $\mathrm{x}$ - and $\mathrm{y}$-directions show no effect of the arm angle on the PSDs with both the light and tight gripping of the steering wheel as in Figure 9. With the arm at angle position, the PSDs of the z-acceleration of the head increased in the frequency range $1.5 \mathrm{~Hz}$ to the frequency of the main peak (at around $4 \mathrm{~Hz}$ ) and decreased but only slightly at and above the frequency of the main peak compared to the arm extended position (Figure 9). This is true for both steering wheel gripping conditions (i.e. light gripping and tight gripping). The difference in the PSD between the arm extended and arm at angle positions at frequencies above the main peak is more pronounced with the light gripping than with the tight gripping of the steering wheel. This explains the higher r.m.s. value of the z-acceleration of the head when the arms were extended especially with the steering wheel light-gripping condition. As the seat position was fixed, the subjects had to push their backs against the backrest (which damped the motion of the backrest) in order to achieve the arm extended position while they sat relaxed with the arm at an angle position. This might have reduced the contribution of the backrest vibration and the steering wheel vibration to the acceleration of the head at low frequencies when the arms were extended. However, at high frequencies the angle between the arms might have damped the vibration received from the steering wheel. This argument does not apply to the lateral direction as bending the arms would not help in damping the motion in the lateral direction. With the body resting on an inclined compliant backrest, the position of the arms (or any other body part such as the legs) is not expected to affect the motion of the head in the lateral direction except if the vibration is applied directly to the head as in the case of using a headrest. Toward and Griffin [18] investigated the effect of the horizontal position of the steering wheel on the vertical apparent mass and reported an increase in the apparent mass at $4 \mathrm{~Hz}$ when the steering wheel was moved from the closest position (similar to arm at angle) to the furthest position (similar to arm extended). Although this is consistent with the result obtained for the PSDs of the vertical acceleration of the head, no similarities were found between the two studies at other frequencies. The $4 \mathrm{~Hz}$ peaks in the apparent mass and in the PSD of the acceleration of the head could be correlated as previous studies showed good agreement between the apparent mass and the seat-to-head transmissibility in the $4 \mathrm{~Hz}$ region [25]. 


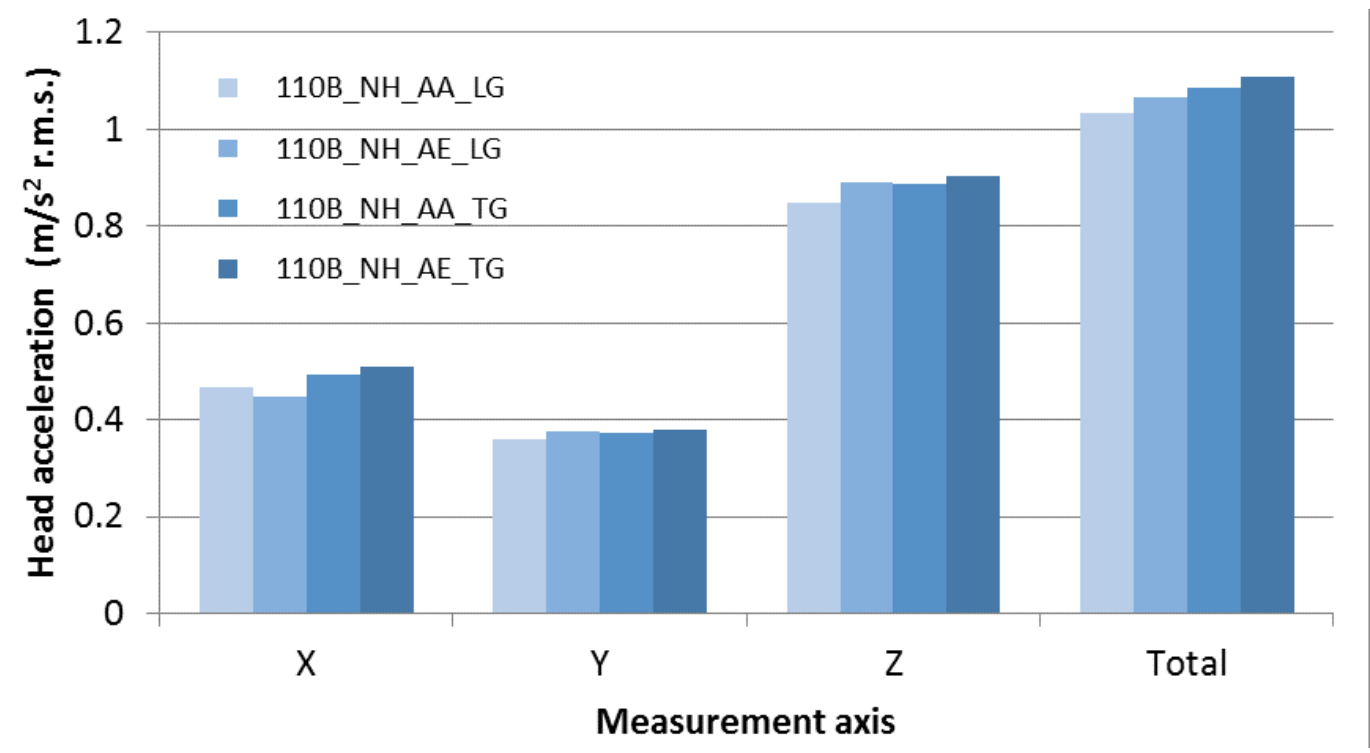

Figure 8. Effect of the arm angle and the extent of gripping the steering wheel on the r.m.s. value of the acceleration of the head.

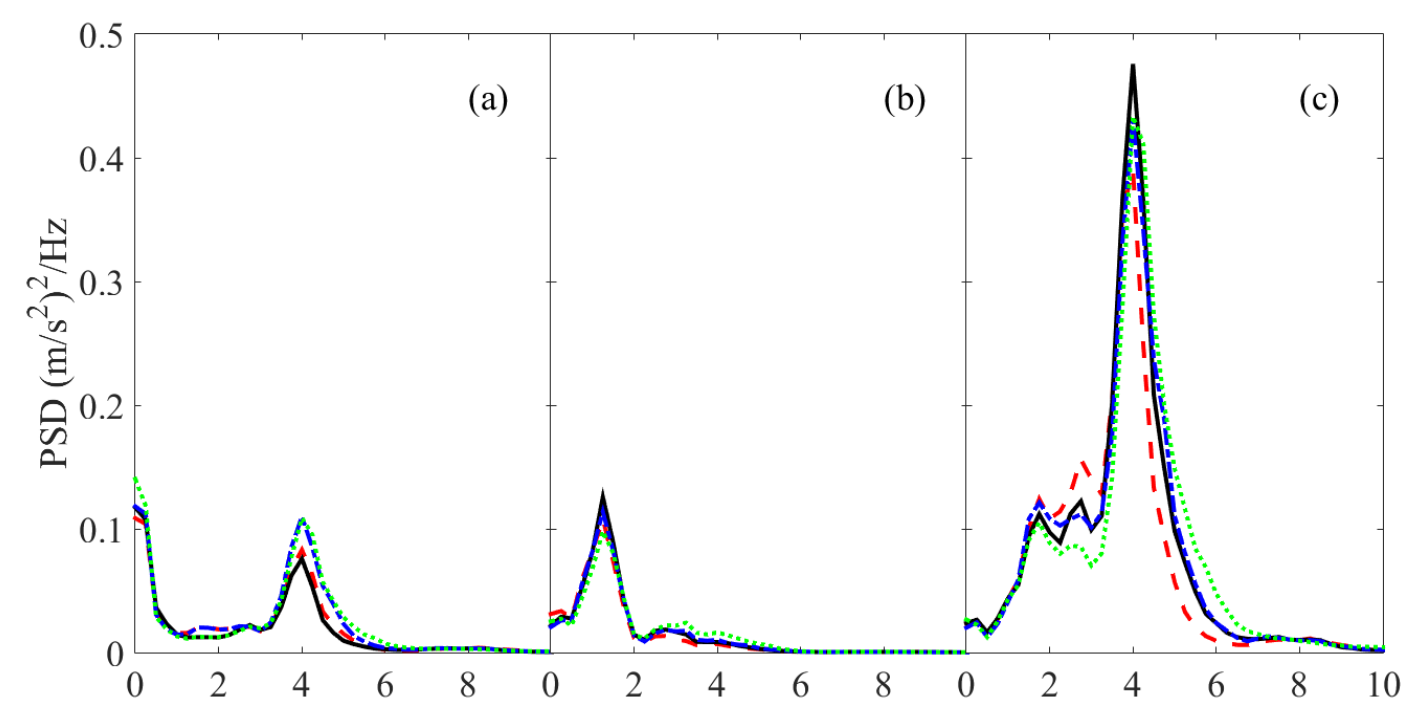

Figure 9. Effect of the arm angle and the extent of gripping the steering wheel on the PSD of the acceleration of the head. (a), x-axis; (b), y-axis; (c), z-axis. Solid line, 110B_NH_AE_LG; dashed line, 110B_NH_AA_LG; dash-dot line, 110B_NH_AA_TG; dotted line, 110B_NH_AE_TG.

Generally speaking, the effect of arm position on the acceleration of the head was found small consistent with the results of [3] who reported small effect of using a steering wheel on the seat-to-head transmissibility. The small effect of the arm angle is also consistent with the results obtained by [29] who reported little influence of arm angle on the transmissibility to the head during both random and sinusoidal vertical vibration. However, this does not rule out the importance of hand position when modelling the exposure of the human body to vibration as the same study found an influence for the arm angle on the transmissibility to other locations on the body such as the thigh and shin. In addition, arm position has been reported to affect the apparent 
mass during single axis vibration [30] and the effective transmissibility to the head during multi-axis vibration [8]: differences were reported between the biodynamic responses measured when the subjects used a steering wheel and those measured when the subjects had their hands in their laps or rested their arms on an armrest.

\section{Effect of the Degree of Gripping the Steering Wheel}

The effect of the degree of gripping the steering wheel on the motion of the head was investigated using two gripping cases defined as light gripping and tight gripping (Figure 8). The effect of gripping the steering wheel was studied once with arms at an angle (i.e. the seating conditions 110B_NH_AA_LG and 110B_NH_AA_TG) and once with arms extended (i.e. the seating conditions 110B_NH_AE_LG and 110B_NH_AE_TG). With both arm positions, statistical analysis showed that gripping the steering wheel tightly increases only the fore-and-aft acceleration $(x)$ of the head (Wilcoxon, $p<0.05$, Table 2) and has no effect on the accelerations of the head in the $\mathrm{y}$ - and z- directions.

With both arm positions, gripping the steering wheel tightly increased the PSD of the x-acceleration of the head above $3 \mathrm{~Hz}$. This explains the increase in the r.m.s. value of the $x$-axis acceleration of the head when gripping the steering wheel tightly. Depending on the frequency, the PSD of the $y$ - and z-accelerations of the head, increased, decreased or did not change with altering the degree of gripping the steering wheel (Figure 9). Those observations are consistent with the absence of an effect for the degree of the steering wheel gripping on the r.m.s. values in both the $\mathrm{y}$ - and $\mathrm{z}-$ directions. In all directions, however, the difference between the result obtained with tight gripping and those obtained with light gripping is small. This seems to be consistent with the results obtained by [28] who reported no effect of the vibration of the steering wheel on the transmission of vibration through the human body. This, however, does not rule out the importance of considering the contact with a steering wheel when modelling the exposure of the driver to vibration as previous studies showed that hand contact affect the apparent mass of the human body [18].

The results of the current work were obtained using a real life multi-axis vibration environment. The results of this study would be better discussed with the availability of enough data about the responses to multi-axis vibration and particularly with those measured in real life vibration environment. Nevertheless, the results imply that there are differences between the responses obtained in a real-life environment and those obtained in the lab using single, dual or tri-axial exposure to vibration. This indicates the need for more representative multi-axis experiments and models to understand the effect of vibration on comfort, health and interference with activities in a real-life setup.

\section{CONCLUSION}

The effect of the seating condition (using a backrest, angle of the backrest, using a headrest, arm angle, and the degree of gripping the steering wheel) on the acceleration of the head of a car driver was investigated in a real life multi-axis environment. The greatest effect on the acceleration of the head came from using the backrest and the headrest. The arm angle and the extent of gripping the steering wheel showed no or little effect on the acceleration of the head. The effect of the seating condition was found generally different from that reported in studies conducted in the labs with single, dual, 
or tri-axis vibration exposure. This indicates the need for more representative multi-axis experiments and models to understand the effect of vibration on comfort, health and interference with activities in a real-life setup.

\section{ACKNOWLEDGEMENT}

The author would like to thank the University of Sharjah for the financial support of the project. The author would like also to thank Engineer Sadeque Hamdan for the time and effort he put to format the paper as required by the journal. The help provided by Engineers Mohamed Danesh, Ahmad Qasem, and Mohanad Hisham is highly appreciated. The author is also thankful to all subjects who took part in the experiment.

\section{REFERENCES}

[1] Nawayseh N, Griffin MJ. Power absorbed during whole-body fore-and-aft vibration: Effects of sitting posture, backrest, and footrest. Journal of Sound and Vibration 2012;331:252-62.

[2] Liu C, Qui Y, Griffin MJ. Dynamic forces over the interface between a seated human body and a rigid seat during vertical whole-body vibration. Journal of Biomechanics 2017;61:176-82.

[3] Mandapuram S, Rakheja S, Boileau PÉ, Maeda S. Apparent mass and head vibration transmission responses of seated body to three translational axis vibration. International Journal of Industrial Ergonomics 2012;42:268-77.

[4] Mandapuram S, Rakheja S, Marcotte P, Boileau PÉ. Analyses of biodynamic responses of seated occupants to uncorrelated fore-aft and vertical whole-body vibration. Journal of Sound and Vibration 2011;330:4064-79.

[5] Mansfield NJ, Maeda S. The apparent mass of the seated human exposed to single-axis and multi-axis whole-body vibration. Journal of Biomechanics 2007;40:2543-51.

[6] Mansfield NJ, Maeda S. Comparison of the apparent masses and cross-axis apparent masses of seated humans exposed to single- and dual-axis whole-body vibration. Journal of Sound and Vibration 2006;298:841-53.

[7] Dewangan KN, Shahmir A, Rakheja S, Marcotte P. Seated body apparent mass response to vertical whole body vibration: Gender and anthropometric effects. International Journal of Industrial Ergonomics 2013;43:375-91.

[8] Rahmatalla S, Deshaw J. Effective seat-to-head transmissibility in whole-body vibration: Effects of posture and arm position. Journal of Sound and Vibration 2011;330:6277-86.

[9] Jack RJ, Eger T. The effects of posture on seat-to-head whole-body vibration transmission. Journal of Low Frequency Noise, Vibration and Active Control 2008;27:309-25.

[10] Singh I, Nigam SP, Saran VH. Effect of Backrest Inclination on Sitting Subjects Exposed to WBV. Procedia Technology 2016;23:76-83.

[11] Ahn SJ. Discomfort of vertical whole-body shock-type vibration in the frequency range of 0.5 to $16 \mathrm{~Hz}$. International Journal of Automotive Technology 2010;11:909-16.

[12] Nawayseh N, Griffin MJ. Effect of seat surface angle on forces at the seat surface during whole-body vertical vibration. Journal of Sound and Vibration 2005;284:613-34. 
[13] Nawayseh N. A mathematical model of the apparent mass of the human body under fore-and-aft whole-body vibration. International Journal of Automotive and Mechanical Engineering 2016;13:3613-27.

[14] Nawayseh N. Effect of the seating condition on the transmission of vibration through the seat pan and backrest. International Journal of Industrial Ergonomics 2015;45:82-90.

[15] Griffin MJ. Handbook of human vibration. London: Academic Press; 1990.

[16] Qiu Y, Griffin MJ. Transmission of roll, pitch and yaw vibration to the backrest of a seat supported on a non-rigid car floor. Journal of Sound and Vibration 2005;288:1197-222.

[17] Rakheja S, Stiharu I, Zhang H, Boileau PÉ. Seated occupant interactions with seat backrest and pan, and biodynamic responses under vertical vibration. Journal of Sound and Vibration 2006;298:651-71.

[18] Toward MGR, Griffin MJ. Apparent mass of the human body in the vertical direction: Effect of a footrest and a steering wheel. Journal of Sound and Vibration 2010;329:1586-96.

[19] Nuawi MZ, Ismail AR, Nor MJM, Rahman MM. Comparative study of whole body vibration exposure between train and car Passengers: A case study in Malaysia. International Journal of Automotive and Mechanical Engineering 2011;4:490-503.

[20] Ismail AR, Abdullah SNA, Abdullah AA, Deros BM. Whole-body vibration exposure of Malaysian taxi drivers. International Journal of Automotive and Mechanical Engineering 2015;11:2786-92.

[21] Welch PD. The use of fast Fourier transform for the estimation of power spectra: A method based on time averaging over short, modified periodograms. IEEE Transactions on Audio and Electroacoustics 1967;15:70-3.

[22] Nawayseh N, Griffin MJ. Tri-axial forces at the seat and backrest during wholebody vertical vibration. Journal of Sound and Vibration 2004;277:309-26.

[23] Paddan GS, Griffin MJ. The transmission of translational seat vibration to the head-II. Horizontal seat vibration. Journal of Biomechanics 1988;21:199-206.

[24] Paddan GS, Griffin MJ. The transmission of translational seat vibration to the head-I. Vertical seat vibration. Journal of Biomechanics 1988;21:191-7.

[25] Wang W, Rakheja S, Boileau PÉ. Relationship between measured apparent mass and seat-to-head transmissibility responses of seated occupants exposed to vertical vibration. Journal of Sound and Vibration 2008;314:907-22.

[26] Wang W, Rakheja S, Boileau PE. Effect of back support condition on seat to head transmissibilities of seated occupants under vertical vibration. Journal of Low Frequency Noise, Vibration and Active Control 2006;25:239-59.

[27] Deshaw J, Rahmatalla S. Effect of lumbar support on human-head movement and discomfort in whole-body vibration. Occupational Ergonomics 2016;13:3-14.

[28] Demić M, Lukić J. Investigation of the transmission of fore and aft vibration through the human body. Applied Ergonomics 2009;40:622-9.

[29] Nishiyama S, Uesugi N, Takeshima T, Kano Y, Togii H. Research on vibration characteristics between human body and seat, steering wheel, and pedals (effects of seat position on ride comfort). Journal of Sound and Vibration 2000;236:1-21.

[30] Rakheja S, Stiharu I, Boileau P-E. Seated occupant apparent mass characteristics under automotive postures and vertical vibration. Journal of Sound and Vibration 2002;253:57-75. 